\section{A Lower Limit to Energy Evolution in Stellar Matter}

IT is well recognized that the energy generation in stellar interiors is due to nuclear reactions in which protons play a dominant part. This circumstance fixes, as is shown here, for stellar material of given density and chemical constitution a lower limit to the rate of energy-generation-the limiting value increasing very rapidly as the density of the material and the proportion of hydrogen in it increases. In the present note we shall only consider the reaction leading to the formation of deuteron by proton combination $\left(\mathrm{H}+\mathrm{H}=\mathrm{D}+\varepsilon^{+}\right)$, though the results discussed here can easily be extended to other nuclear transformations brought about by protons. The probability of this astrophysically important reaction has been recently calculated by Bethe and Critchfield ${ }^{1}$, who conclude that for stars lighter than the sun this process is the main source of energy.

The existence of the lower limit mentioned above for the rate of energy-generation follows at once when we note that the probability of the nuclear reaction is a function of the velocity of the protons, and as the protons obey Fermi-Dirac statistics, there exists for a given value of the proton-concentration (number of protons per unit volume) a 'minimum energy distribution' - the distribution corresponding to a completely degenerate gas. Therefore, the limiting value of the energy-generation for a given protonconcentration $n$ is obtained by averaging the probability of reaction for a velocity-distribution corresponding to that of a completely degenerate proton gas, that is, the limiting value gives the energy-generation when, for a fixed $n$, the temperature $T \rightarrow 0$.

If $\varepsilon_{0}$ denotes the minimum rate of energy-generation per gram of the material, then, following Bethe and Critchfield, with necessary alterations to take account of the new velocity-distribution law, we finally obtain

$$
\varepsilon_{0}=2.4 \times 10^{3} \rho c_{\mathrm{H}^{2}} e^{-}
$$

where $\rho$ is the density of the material, $c_{\mathrm{H}}$ the proportion of hydrogen by weight, and $z$ is given by

$$
z=4 \pi^{2}\left(\frac{\pi}{3}\right)^{1 / 3} \frac{m_{\mathrm{H}} e^{2}}{\overline{h^{2} n^{1 / 3}}}=4.2 \times 10^{3} \frac{1}{\left(. c_{\mathrm{H}}\right)^{1 / 3}},
$$

where $m_{\mathrm{H}}$ is the mass of the hydrogen atom, $e$ the electron-charge and $h$ is Planck's constant.

In the following table the values of $\varepsilon_{0}$ are given for different densities for the case of $c_{\mathrm{H}}=1$ (all hydrogen) and $c_{\mathrm{H}}=0.3$ (30 per cent hydrogen).

MINIMUM ENERGY EVOLCTION FOR DIFFERENT DENSITIES AND

\begin{tabular}{|c|c|c|c|c|}
\hline Density $\left(\mathrm{gm} . / \mathrm{cm}^{3}\right)$ & $10^{6}$ & $5 \times 10^{6}$ & $10^{\circ}$ & $5 \times 10^{7}$ \\
\hline $\begin{array}{c}\varepsilon_{0} \text { for } c_{\mathrm{H}}=1, \\
(\mathrm{erg} / \mathrm{gm} . \mathrm{sec} .)\end{array}$ & $1.4 \times 10^{-0}$ & $0 \cdot 26$ & 82 & $1.3 \times 10^{6}$ \\
\hline $\begin{array}{c}\varepsilon_{0} \text { for } c_{\mathbf{H}}=0 \cdot 3, \\
(\mathrm{erg} / \mathrm{gm} . \mathrm{sec} .)\end{array}$ & $1.2 \times 10^{-10}$ & $1.3 \times 10^{-7}$ & $4.9 \times 10^{-4}$ & $4.3 \times 10^{2}$ \\
\hline
\end{tabular}
HYDROGEN CONCENTRATION

It will be seen that $\varepsilon_{0}$ varies extremely rapidly with $\rho$ and $c_{H}$. In the case of degenerate proton gas, the rate of energy-generation for a given $p$ and $c_{\mathrm{H}}$ will not differ much from the value corresponding to complete degeneracy, but for non-degeneracy it will obviously be widely different.
The existence of a lower limit to the rate of stellar energy-evolution is particularly significant in connexion with the white dwarf stars (and also nuclei of planetary nebulæ). These applications, however, will be discussed elsewhere.

\section{S. Kothart.}

Physics Department,

University of Delhi.

Oct. 6.

${ }^{1}$ Bethe and Critchfleld, Phys. Rev., 54, 248 (1938).

\section{Seismic Methods in Submarine Geology}

Prof. Maurice Ewing has shown that it is possible to use the seismic method for investigating submarine geology, and has used the method to show that, in the continental shelf off the coast of Virginia, many thousands of feet of sediments overlie the Palæozoic or pre-Cambrian rocks.

The Royal Society recently appointed a Committee with Rear-Admiral Edgell, hydrographer of the Navy, as chairman, to organize similar measurements on the eastern side of the Atlantic. The Lords Commissioners of the Admiralty made H.M. surveying ship Jason available for the purpose, and she was anchored successively at five stations on a line extending 170 miles west-south-west from the Lizard, and at each station geophones were lowered to the sea bottom. The geophones were connected to recording apparatus in the ship and records were made of the ground motion produced by the explosion of charges of up to $62 \mathrm{lb}$. of T.N.T. laid on the sea floor and fired from a motor-boat.

Forty-six records, mostly of satisfactory quality, were obtained, and time-distance curves were constructed. The first station was four miles south of the Lizard; the velocity of elastic waves in the surface rocks was $11,000 \mathrm{ft} . / \mathrm{sec}$; this is too fast for recent sediments, but too slow for the igneous rocks of the Lizard. This surface layer was found to be $1,000 \mathrm{ft}$. thick and to be underlain by rocks in which the explosion wave travels with a velocity of $23,000 \mathrm{ft}$./sec.; the latter are presumably the igneous rocks. The occurrence of the $11,000 \mathrm{ft} . / \mathrm{sec}$. layer on top of the igneous rock is of considerable interest, and there is reason to believe from the results of dredging, that it represents an outlier of Trias, and indicates that the Channel was formed along the line of a pre-existing basin.

The next two stations are sixty and eighty miles west-south-west of the Lizard, and they showed $550 \mathrm{ft}$. and $1,000 \mathrm{ft}$. of sediments with a transmission velocity of 6,000-7,000 ft./sec. At the two outer stations (115 and 170 miles west-south-west of the Lizard), only lower limits can be set to the thickness of the sediments, as bad weather prevented very long lines from being shot. At the outermost of these stations the records are of excellent quality and show that there is certainly no rock having high transmission velocity similar to that found at the other three stations within $4,000 \mathrm{ft}$. of the surface. The next station shows that there are not less than $2,000 \mathrm{ft}$. of sediments.

It has been established, therefore, that a substantial part of the continental shelf is composed of relatively unconsolidated rocks. Measurements of the velocities of elastic waves in the rocks of Cornwall and Devon are to be made in the near future. 